\section{Do Saber Sem Qualidades À Qualidade Da Formação no Que Não Se Pode ENSINAR :}

teoria crítica, método estrutural e um programa mínimo à investigação e formação filosóficas

\section{Gilberto Tedéia}

\section{Professor de Filosofia - UnB}

Resumo :O artigo tem como objeto o ensino e pesquisa na área da filosofia no interior da universidade, tanto alguns de seus limites como algumas formas de ação pedagógica que possam superá-los. Após tomar como ponto de partida a máxima de que não se ensina filosofia, mas a filosofar, aponta como se realiza essa tarefa no interior universidade brasileira, repõe uma crítica à especialização dessa atividade, e, por fim, apresenta algumas diretrizes para o trabalho de formação do aluno e pesquisador nessa área. Se inicia com um diagnóstico sombrio do presente, marcado pela quantificação da produção filosófica como padrão de medida do seu valor e da importância de seu autor. Retoma a crítica tecida por Horkheimer em Teoria Tradicional e Teoria Crítica à especialização imposta mediante recorte metodológico que se consolida como modelo de atividade científica e de sua institucionalização. Por fim, conclui repondo algumas diretrizes básicas para uma relação formadora e consistente do iniciando na área de filosofia nos cursos de graduação e pós-graduação com os contornos de uma formação filosófica e científica, retomando a estratégia pedagógica estrutural para apresentar formas de pensar a formação filosófica mediante a defesa de certo modo de ler e analisar textos.

Palavras-chave: método estrutural; Horkheimer; teoria crítica; ensino de filosofia; pesquisa filosófica

\footnotetext{
Abstract: The article aims to analyze philosophy teaching and research in the university, as well some of its limits and forms of pedagogical action that can overcome them. After taking as a starting point the Kantian precept that it is impossible to teach philosophy, the first step is to point out how to perform this task within Brazilian university. The
}

second step is to show a critique of specialization of this activity. Finally, it presents some guidelines for the education of students and research in this area.

Keywords: structural method; Horkheimer; Critical theory; philosophical teaching; philosophical research

$\mathrm{O}$ ponto de partida do artigo retoma o invento kantiano que acaba com a metafísica, quando então entra em cena o fim da longa história da relação da filosofia com "objetos" exteriores ou anteriores ao pensar, e entra em cena as condições de possibilidade de pensá-los, os objetos. Esse invento se desdobrou naqueles poucos e intensos anos que marcam o intervalo entre a publicação da Crítica da Razão Pura e a morte de Hegel, 1787 a 1831, a reinventarem a filosofia, anos dos quais somos todos, ou contra ou a favor ou a superar ou apesar de herdeiros (cf. ŽIŽEK, 2013, p. 17-21, passim).

Dentre as várias dimensões apostadas por aquele ponto de partida, destaque-se uma terminologia filosófica que acaba com a pretensão do filósofo de falar para o mundo antes, mesmo Espinosa achava estar falando para o mundo. Com Kant, na esteira do projeto da Aufklärung (cf. KANT, 2009, primeiro e último parágrafo), com a defesa do uso da razão a submeter a santidade da religião ou a majestade do poder à análise visando a saída da humanidade das trevas da ignorância e da dominação (cf. comentário de TORRES FILHO, p. 89-90, passim), a filosofia passa a usar uma terminologia específica que exige uma iniciação adequada, e eis que os cursos de filosofia tornam-se necessários.

Porém outra invenção kantiana parece até contradizer a exigência de iniciação, e pode ser assim formulada: "Filosofia não se ensina. Ensina-se o filosofar" (cf. entre outros, MAUGÜÉ, 1955, p. 642). Sem objeto e não se ensina filosofia, tendo que reinventar uma coisa à qual ao mesmo tempo tem de ser praticada, e, no contexto do ensino da filosofia 
hoje, três serão as dimensões a serem aqui tratadas para dar conta dessa tarefa.

\section{O que significa filosofia na universidade no Brasil hoje?}

Além da dimensão que pensa como o conceito de filosofia exige lidar com as condições da interpretação filosófica, a ser tratada na última parte do artigo, surge a dimensão da prática da filosofia. Nesse âmbito, o debate crítico reconhece a dimensão do "fazer filosófico" reduzido ao que pode ser mensurado e reputado tão somente em função da quantificação da produção e sua qualificação segundo indicadores que privilegiam algumas variáveis nos termos das quais se mensura e avalia a publicação que traz o texto.

Um primeiro efeito que pode ser apontado aqui é a desqualificação do trabalho do professor em sala de aula. Tais variáveis desdenham do ofício docente e considera irrelevante a carga de trabalho que uma boa aula e o ano ou semestre letivo em que esteja contida exigem para sua preparação e maturação ser refeita após o termo do período, quando a bibliografia será repassada e algumas costuras serão feitas para, após uma segunda exposição, o período letivo ser repensado em seu conjunto após o termo de seu percurso, e então, revisado o percurso, dele sair o tema a ser aprofundado em um artigo ${ }^{1}$.

Ao ser reduzido à dimensão de textos publicáveis, o trabalho do professor universitário em sala e sua relação com o aluno, a sua relação com a atividade-fim do ensino universitário, transforma-se em estorvo. Não raro contornado com estratagemas vários. Há o professor que coloca orientandos em seu lugar na sala de aula [e existe um programa institucionalizado pelo governo federal que viabiliza, legitima e estimula essa "saída", a pretexto de qualificar o orientando]. Há aquele cujas aulas se restringem à reposição sumária de algum esquema didático exposto em manuais de filosofia pelos quais se expõe em visão panorâmica a abordagem temática ou a histórica - casos em que se perde o mais importante em uma aula de filosofia, que é ensinar ao aluno a filosofar na companhia do autor, ensinar-lhe o cuidado com a argumentação tecida no texto posto pelo autor, seja segundo a ordem lógica das razões, aspecto que o artigo tratará mais adiante, seja em diálogo com outros textos.

O segundo efeito a ser apontado na redução da materialidade da prática filosófica a critérios quantificadores é não apenas impor vistas grossas ao conteúdo do que se faz como "filosofia" em sala de aula, como também desdenhar o conteúdo das próprias publicações e de tudo o mais que caracteriza a vida acadêmica, subsumindo-o ao meramente quantificável. Aqui emerge um pressuposto não assumido: a restrição da obra filosófica à dimensão meramente formal dos indicadores é o recorte que impõe, como padrão de medida não explicitado, que o bom conteúdo será aquele reconhecido e citado $\mathrm{Y}$ vezes pelos pares ou o estampado nas páginas de revistas com índices altos, de preferência A1, nesse sistema de precificação insana que é a avaliação Capes - insana, pois a "mercadoria precificada" é meramente simbólica e a materialidade do "avaliado" é a geração de um índice a servir de padrão de medição válido

\footnotetext{
${ }^{1}$ Esse percurso é o segredo soprado pelo Antonio Candido a Paulo Arantes, por sua vez repassado em reunião do Grupo da Quartas, grupo interdisciplinar há muitos anos secretariado por Anderson Gonçalves, que se reúne FFLCH-USP quinzenalmente desde 1999, como marca de um modo de trabalho intelectual atropelado pelos ares dos tempos de que se tratará a seguir.
} 
para si mesmo, por si mesmo a impor um em $s i$, o número de pontos que a tudo o mais submete à sua lógica, a começar nota da publicação e da revista, passando pela política de concessão de bolsas até chegar à avaliação do departamento, o montante de verbas a que ele terá direito, o credenciamento ou descredenciamento de seus cursos bem como o do professor.

\section{A pesquisa em filosofia segundo Horkheimer}

Por que a dimensão da prática filosófica reduzida ao caçador de pontos e publicações precisa ser destacada? A resposta a essa pergunta retoma o fio da crítica à quantificação redutora de ideias qualitativamente distintas já lá na década de 30 em Frankfurt, pelos pesquisadores do Instituto de Pesquisas Sociais. Na formulação do texto que pode ser dito um "manifesto" dessa geração de pesquisadores, o Teoria Tradicional e Teoria $\mathrm{Crítica}^{2}$, é preciso explicitar nexos materialmente constitutivos da relação entre o saber produzido, as formas de sua apropriação social, as condições de sua produção e as implicações de se segmentar o objeto "homem" em áreas estanques e "autônomas" de conhecimento.

Dada a diversidade de âmbitos em que a prática de produção de conhecimento mostra as diferentes dimensões da práxis social da pesquisa científica, impõe-se um registro metodológico que abstrai e mensura qualidades, pelo qual dogmaticamente se exige um recorte que mensura as diversas relações entre sujeito e objeto - entre o sujeito do conhecimento, o da ação, o da obra de arte, o da política, e o seu respectivo objeto.

A crítica à quantificação faz emergir, seguindo na companhia de Horkheimer, algo que a práxis imposta como pressuposto à pesquisa em geral, a filosófica aí incluída, escamoteia. O âmbito a ser destacado é o descurado e escamoteado como irrelevante: a contradição fundamental que organiza as relações sociais, que é, tal como o ensinaria a crítica da economia política, a relação entre o capital e sua apropriação privada que ele opera dos ganhos advindos do produzido socialmente pelo mundo do trabalho.

Uma vez que o edifício do saber funciona sem considerar o solo dos interesses sociais que o organiza, o fruto dessa práxis é abrirem-se, como regiões autônomas do saber, as diversas dimensões da pesquisa científica - as das ciências da natureza, biológicas, tecnológicas e as do homem -, segundo um longo trabalho de séculos de apuro metodológico pelo qual se edifica o sistema das ciências e da produção de saber.

Voltando ao contexto universitário de que partíramos antes, nesse oceano de práticas objeto da crítica de Horkheimer, o sistema Capes de mensuração é apenas a nossa gota de contribuição local à história da consolidação do modelo tradicional de produção da teoria e reprodução de práticas científicas, pela qual também nossa vida filosófica se mostra colonizada por indicadores exteriores à sua singularidade, a institucionalizar mecanismos de controle e medição que atropela até mesmo o longo tempo outrora necessário e usual para a produção filosófica. Quanto ao tempo da reflexão colonizado pela formalização do saber a ser apresentado, hoje ele está reduzido às dimensões impostas por esse sistema nos programas de mestrado e doutorado, que impõem uma janela temporal ao aprendizado, ensino e pesquisa em que os tempo de investigação filosófica e escrita de dissertações

\footnotetext{
${ }^{2}$ Para o que se segue, cf. HORKHEIMER, 1983, p. 117-154.
} 
e teses é mais apropriado para a de um opúsculo ou um artigo mais robusto, se muito.

\section{Como formar o aluno no que não pode ser ensinado?}

Quando o assunto seja a dimensão da investigação filosófica, a do cuidado com o conteúdo mesmo do que se faz, propõe-se aqui remontar à história de um implante que foi a importação de professores franceses de filosofia na recém-criada Faculdade de Filosofia da Universidade de São Paulo (para o que se segue, cf. ARANTES, 1994), que trazem na bagagem o método estrutural de leitura e análise de textos, um modo de lidar com a interpretação de textos filosóficos buscando neles o movimento que entrelaça o que se diz com o modo como se diz. Isso implica, como aponta Jean Magüe, ler textos de filosofia ao invés de comentadores ou manuais, bem como perder o gosto pelo novidadeirismo, e voltarmos aos clássicos neles encontrarmos as raízes de uma questão que contemporânea (cf. MAUGÜÉ, 1955, p. 644-647). Essa premissa metodológica inaugura um modo de se ler textos de filosofia e certa relação com o que seja o assunto "filosofia", que abrem um debate que, desde a mesa "Por que filósofo?" (cf. TORRES, GIANNOTTI, LEBRUN et al., 1976, p. 133-176), é objeto de vasta teorização nacional nas mesas e publicações filosóficas, em dimensões conceituais que aprofundam o debate em dimensões muito além do recorte posto nesse artigo.

Volte-se à questão inicial, agora em novo registro: como essa tradição ajudaria lidar com a amplitude dos impactos postos por esse pressuposto quantificador, sobretudo com seu impacto entre os iniciandos nesse processo quando ingressam nos programas de graduação e pós-graduação?

Propomos a captura da prática filosófica pela lógica quantitativista em uma visada crítica. Suponha-se como objeto um congresso de filosofia. Trata-se de propor trazer ambos os públicos desses programas, o graduando e o pós-graduando, também como produtores de saber. Não é mais possível pensar a produção do pensamento segundo um modelo de filósofo fechado na solidão de seu gabinete, e nem se refere aqui a aberrações como a do franco atirador isolado que escreve em alemão no interior do Nordeste como foi o caso de Tobias Barreto, o problema é de outra ordem.

Para lidar com a nova configuração da universidade, os Grupos de Pesquisa são a ocasião que instaura a nova sociabilidade que atravessa um modo de pensar a realização da filosofia, pela qual ela se torna ler e falar de. $\mathrm{O}$ que seja ler um texto de filosofia exige agora a entrada em cena da dimensão do "saber fazer" contido na preocupação com as dimensões da prática filosófica a ser trabalhada no ensino disso que não se pode ensinar.

Esse saber-fazer remonta ao desembarque do método francês nos anos 30, quando começa a dar seus frutos nos anos 50, um dos quais é a filosofia se firmar no interior do sistema universitário. Como aponta Giannotti ${ }^{3}$, o fato é que ainda se coloca dinheiro público para fazer aparecer jovens rebeldes que formam uma comunidade imaginária que contestam o sistema. Há fundos públicos investidos na formação de um tipo de especialista em diálogo imaginário com uma comunidade virtualmente conectada de modo simbólico, e constituída por pessoas que dizem não ao sistema. Nos termos dessa leitura, podemos

\footnotetext{
${ }^{3}$ Para o que se segue, cf. o autor em TORRES, GIANNOTTI, LEBRUN et al, 1976, p. 145-147.
} 
dizer que formamos pessoas que, querendo falar da terra arrasada que é a política de "cunhas, mendes e moros lobo do homem", usam Hobbes para pensar o que seria de um agrupamento sem o pacto social, caso em que estariam todos entregues à fúria do mais forte sem rédeas e pisotear quem bem queira ou, valendo-se de Agamben, mostra como tal cenário realiza um paradigma jurídico administrativo em que a exceção virando regra acaba por esfarelar o que se entenda por estado de direito ${ }^{4}$.

O perfil do aluno que chega aos cursos de filosofia é o do pensador com impulso filosófico de querer se apropriar de conceitos para falar do mundo. É quando se faz necessário assumir uma dimensão propedêutica, na qual a meta de sua formação para a investigação filosófica, quantificável ou não, é o aprendizado da relação a ser mantida com as ideias e questões dos textos e áreas de conhecimento com as quais entrará em contato.

Visando garantir uma dimensão a um só tempo filosófica e científica no processo formador do aluno, essa relação atende pelo nome de método estrutural de leitura e análise de textos, conforme, entre outros Goldschmidt (1963). Este ponto de partida pode ser desdobrado em várias direções, dentre as quais a das leituras que buscam a intertextualidade que convoca um texto ao diálogo com, dentro ou suprassumido em outro autor ou sistema filosófico, tal como foi exposto pelo professor Erick Calheiros em sua Conferência nesse seminário.

O momento inicial, que o capacitará até mesmo a se transformar na esperada máquina de produção de indicadores, institui o aprendizado de técnicas que conferem densidade e relevância ao que se faça em sala de aula: mostrar que um argumento tem começo, meio e fim, que as teses se sustentam, que não se pode apenas compor um mosaico a justapor de modo sincrônico ou diacrônico textos e conceitos que estão em diferentes registros de validação.

É quando se aprende não ser possível a justaposição das teses de Hauser e Gombrich sobre a arte italiana como se estivessem tratando seu objeto do mesmo modo. Tampouco interditar a um curso temático a investigação da história que leva à formação de um conceito, por exemplo, da noção de experiência de Descartes, Locke e Hume a Kant: esse debate, no momento da formação do aluno, interessa mais por ele poder reconstruir como o debate foi tecido, ao invés de se restringir ao estado atual da questão.

A retomada da dimensão histórica de questões postas pelo presente confere relevância para $o$ trabalho do filósofo, mais do que o novidadeirismo de se restringir ao último paper da área. Ademais, ilude-se quem se restrinja ao presente supondo nisso conquistar alguma relevância no debate com cientistas, pois - e essa crítica já aparece lá em Husserl, por exemplo - a conformação da comunidade científica relega seu interesse em fundamentos metateóricos de suas experiências a nada, quando muito, volta-se ela aos contornos metodológicos das condições de construção de amostragem e produção de inferências causais na formulação de leis gerais segundo o registro reconhecido como válido no interior de sua respectiva ciência particular.

Não se ignora aqui os diversos limites ao trabalho de formação que tome o método estrutural como ponto de partida. Há o pressuposto cético que o organiza a nivelação de todos os sistemas em idênticos sistemas de validação, ao recusar a eles suas pretensões de

\footnotetext{
${ }^{4} \mathrm{O}$ último exemplo é uma leitura posta por diferentes filósofos e sociólogos sobre o que se passa em diversos quaseEstados pelo planeta afora, três deles na América Latina: Honduras, Paraguai e Brasil.
} 
verdade em geral ao aceitar a pretensão de verdade de cada um deles em particular, como o faria um hegeliano5. Ou mesmo, como aponta Bento Prado, na aula inaugural de seu curso de 1966, o pressuposto metafísico de uma verdade sim a ser exposta, a que cabe ao intérprete explicitar (cf. PRADO JUNIOR, 2008, p. 390-392).

O trabalho de formação do iniciando em filosofia, contudo, não atinge esses limites, porque as técnicas de leitura que o método estrutural aporta à formação servem de porta de entrada para o específico do trabalho filosófico, tal como, em uma analogia com a música ou a dança, o aprendizado do sistema tonal e da dança clássica são sim a propedêutica que conferem consistência e profundidade nos estudos, respectivamente, de música e dança contemporâneas, sob pena de se reinventar a roda tosca e ingenuamente.

Estamos às voltas com o momento de alfabetização nos elementos mínimos necessários ao trato com conceitos e problemas filosóficos e à pesquisa na graduação. É quando os Grupos de Estudo e Pesquisa se apresentam como privilegiada extensão do trabalho desenvolvido em sala de aula e nas leituras extra-aula, quando se trabalha na exposição das ideias de alguém, uma escola, um problema, para além do mero resumo e fichamento de textos.

A graduação é o momento pelo qual o graduando entra em contato com a pluralidade de formas e recortes postos pela pesquisa filosófica. $\mathrm{Na}$ estética, as diferentes relações com objetos, do ponto de vista da obra, do autor e da recepção. Na lógica, as diferentes instanciações que vão da silogística à lógica modal. Na ética e filosofia política, os muitos registros de valores que organizam camadas de significação da ação individual e a instauração de múltiplos nexos na comunidade dos homens, as muitas formas de pensar a relação entre vontade individual e vontade coletiva, ou entre liberdade, acaso e necessidade.

A lista é longa, apenas nos atenhamos a ilustrar com esses exemplos a amplitude do alcance que o método estrutural alcança quando instituiu seu modo de lidar com a leitura e análise de textos. Pouco importa o lugar de onde emerge a fala o filósofo. Em comum a todos eles há o percurso histórico-conceitual a ser reposto de modo rigoroso por quem entra em contato com seu trabalho, e a meta do leitor é demonstrar como o movimento das ideias no interior do argumento tece o percurso valida uma relação consistente entre o que se diz e o modo como as coisas são ditas. Como será esse percurso, que relação é essa, o que ele pensará como padrão de medida da consistência a ser aceita, o conteúdo do que vai ser dito, é aí que cada leitor e cada autor terá de ver em sua singularidade - e o encontro desse patamar é o que permite pensar alguns parâmetros mínimos para a pesquisa, o ensino e a transmissibilidade do conhecimento filosófico.

Diante do fato de que é nesse momento que o lado árduo da profissão do professor emerge: a hora da correção dos trabalhos e provas. Não basta-lhe dizer "você não leu o texto". Seria preciso mostrar, a cada passo da argumentação tecida pelo aluno, quais mediações não foram feitas, onde houve abuso no uso da terminologia ao não se explicitarem determinados pressupostos, quais passagens seriam necessárias serem tecidas para que $\mathrm{o}$ argumento se sustentasse.

Sabe-se que os termos "texto" e "tessitura" tem a mesma origem, que remete a certa trama a ser costurada, e aprender a fazer essa costura é o segredo a ser decifrado nos estudos de iniciação filosófica. De saída, esse percurso pode ser exposto de modo sumário tal como Paulo Vieira Neto o apresenta: há de se

${ }^{5}$ Cf., por exemplo, a revisão dos pressupostos histórico-filosóficos desse método em MOURA, 1988. 
reconhecer quatro camadas de produção de uma leitura e de postura do leitor diante de um texto filosófico: a análise, o comentário, a interpretação e a crítica (VIEIRA NETO, 2006, p. 17-19). Cabe à análise o momento inicial em que se buscar repor a lógica interna segundo a ordem das razões que estrutura o argumento; ao comentário, a tentativa de lidar com as dificuldades da leitura em repor essa lógica mediante o apoio em outras partes do texto; a interpretação seria a leitura que, refazendo todo o percurso desde a análise, visa identificar os pressupostos dos comentários e discernir os campos de significações por eles propostos; por fim, a crítica seria o tipo de leitura amadurecida a percorrer todas as etapas anteriores em busca de o que o texto inicial faça pensar.

Passo seguinte, com Macedo Júnior, podem ser trabalhadas em sala algumas técnicas e passos bem específicos para a reposição da ordem lógica das razões, desde a primeira pergunta, a pelo objeto ou tema do texto, passando pela tese ou ideia central, até a identificação das partes em que sustentam o argumento (cf. MACEDO JÚNIOR, p. 13-41).

Propor essas técnicas é propor uma propedêutica ao aluno, a fim de trabalhar com os pressupostos de ambos esses autores, os apresentados pela leitura canônica da questão por GOLDSHIMDT (1963), nos termos da qual trata-se de evitar tanto a leitura que busca a gênese de uma ideia fora do texto, como a leitura que trata as suas verdades de modo dogmático, o que pode ser até útil num manual para o colégio ou para discentes de outra área, mas não para um aluno no processo de formação na investigação filosófica.

Após passar a limpo essa história, tendo-nos assegurado a consolidação de um sistema de formação filosófica que garanta sua reprodução à larga, satisfeitos todos os defensores dos indicadores uma vez que está garantida a mãode-obra da fábrica de índices, talvez seja a hora de nos vermos com os bloqueios aventados por Horkheimer. Uma vez formado um sistema de ideias passível de ser mensurado em quilômetrosLattes, volta agora a pergunta em nova chave a ser desenvolvida em outra ocasião: por que ainda filosofia?

\section{Referências Bibliográficas}

ARANTES, Paulo Eduardo. Um departamento francês de ultramar. São Paulo: Paz e Terra, 1994.

GOLDSHIMDT, Victor. Tempo histórico e tempo lógico na interpretação dos sistemas filosóficos. In: _. A religião de Platão. São Paulo: Difel, 1963.

HORKHEIMER, Max. Teoria Tradicional e Teoria Crítica. In: , Adorno, Benjamin, Habermas. Obras Escolhidas. São Paulo: Abril, 1983, p. 117-154 [Coleção Os Pensadores]

KANT, Immanuel. Resposta à pergunta: o que é esclarecimento? [tra. V. Figueiredo]. In: ARCAL, Jairo (org.). Antologia de textos de filosóficos. Curitiba: Secretaria de Estado da Educação do Paraná, 2009, p. 406-15.

MACEDO JÚNIOR, Ronaldo Porto. O método de leitura estrutural. In: . (coord.). Curso de filosofia política: do nascimento da filosofia a Kant. São Paulo: Atlas, 2008, p. 13-41.

MAUGÜÉ, Jean. O ensino de filosofia: suas diretrizes. Revista Brasileira de Filosofia, vol.V, n.20. out.-dez.1955, p. 642-9.

MOURA, Carlos Alberto Ribeiro de. História stultitiae e história sapientiae. Revista Discurso, nº 17, 1988, p. 151-71. 
PRADO JÚNIOR, B. Leitura e interrogação: uma aula de 1966. In: A Retórica de Rousseau. São Paulo: Cosac \& Nafy, 2008, p. 375-392.

TORRES, João Carlos Brun, José Arthur GIANNOTTI, Gérard LEBRUN, Rubens Rodrigues TORRES FILHO ("O dia da caça"), José Henrique dos SANTOS ("Filosofia e crítica da ciência), Bento PRADO JÚNIOR ("Os limites da Aufklärung"), in: "Por que filósofo"? Estudos Cebrap, n.15, jan.-mar.1976, p. 133-173.

TORRES FILHO, Rubens Rodrigues. Respondendo à pergunta: quem é a ilustração? In: Ensaios de Filosofia Ilustrada. São Paulo: Brasiliense, 1987, p. 84-101.

VIEIRA NETO, Paulo. O que é análise de texto. In: FIGUEIREDO, V. (org). Seis filósofos na sala de aula. São Paulo: Berlendis \& Vertecchia, 2006, p. 13-19.

ŽIŽEK. Slavoj. Menos que nada: Hegel e a sombra do materialismo dialético. São Paulo: Boitempo, 2013. 